\title{
Vessel Wall and Adventitial DCE-MRI Parameters Demonstrate Similar Correlations With Carotid Plaque Microvasculature on Histology
}

Citation for published version (APA):

van Hoof, R. H. M., Voo, S. A., Sluimer, J. C., Wijnen, N. J. A., Hermeling, E., Schreuder, F. H. B. M., Truijman, M. T. B., Cleutjens, J. P. M., Daemen, M. J. A. P., Daemen, J-W. H., van Oostenbrugge, R. J., Mess, W. H., Wildberger, J. E., Heeneman, S., \& Kooi, M. E. (2017). Vessel Wall and Adventitial DCEMRI Parameters Demonstrate Similar Correlations With Carotid Plaque Microvasculature on Histology. Journal of Magnetic Resonance Imaging, 46(4), 1053-1059. https://doi.org/10.1002/jmri.25648

Document status and date:

Published: 01/10/2017

DOI:

10.1002/jmri.25648

Document Version:

Publisher's PDF, also known as Version of record

Document license:

Taverne

Please check the document version of this publication:

- A submitted manuscript is the version of the article upon submission and before peer-review. There can be important differences between the submitted version and the official published version of record.

People interested in the research are advised to contact the author for the final version of the publication, or visit the DOI to the publisher's website.

- The final author version and the galley proof are versions of the publication after peer review.

- The final published version features the final layout of the paper including the volume, issue and page numbers.

Link to publication

\footnotetext{
General rights rights.

- You may freely distribute the URL identifying the publication in the public portal. please follow below link for the End User Agreement:

www.umlib.nl/taverne-license

Take down policy

If you believe that this document breaches copyright please contact us at:

repository@maastrichtuniversity.nl

providing details and we will investigate your claim.
}

Copyright and moral rights for the publications made accessible in the public portal are retained by the authors and/or other copyright owners and it is a condition of accessing publications that users recognise and abide by the legal requirements associated with these

- Users may download and print one copy of any publication from the public portal for the purpose of private study or research.

- You may not further distribute the material or use it for any profit-making activity or commercial gain

If the publication is distributed under the terms of Article $25 \mathrm{fa}$ of the Dutch Copyright Act, indicated by the "Taverne" license above, 


\title{
Vessel Wall and Adventitial DCE-MRI Parameters Demonstrate Similar Correlations With Carotid Plaque Microvasculature on Histology
}

\author{
Raf H.M. van Hoof, MSc, ${ }^{1,2}$ Stefan A. Vöö, MD, PhD, 1,2 Judith C. Sluimer, PhD, ${ }^{2,3}$ \\ Nicky J.A. Wijnen, BSc, ${ }^{1}$ Evelien Hermeling, PhD, ${ }^{1,2}$ \\ Floris H.B.M. Schreuder, MD, MSc, ${ }^{1,2,4,5}$ Martine T.B Truijman, MD, PhD, 1,2,4,5 \\ Jack P.M. Cleutjens, PhD, ${ }^{2,3}$ Mat J.A.P. Daemen, MD, PhD, ${ }^{6}$ \\ Jan-Willem H. Daemen, MD, PhD, ${ }^{7}$ Robert J. van Oostenbrugge, MD, PhD, ${ }^{2,4}$ \\ Werner H. Mess, MD, PhD, 2,5 Joachim E. Wildberger, MD, PhD, 1,2 \\ Sylvia Heeneman, $\mathrm{PhD}^{2,3}$ and M. Eline Kooi, $\mathrm{PhD}^{1,2 \star}$
}

Purpose: To assess parameter agreement of volume transfer coefficient $\left(K^{\text {trans }}\right)$ between two vascular regions and to study the correlation with microvessel density on histology. The dynamic contrast-enhanced magnetic resonance imaging (DCE-MRI) parameter $K^{\text {trans }}$ is frequently used to study atherosclerotic plaque microvasculature. $K^{\text {trans }}$ has been reported using different descriptive statistics (mean, median, $75^{\text {th }}$ percentile) either for the whole vessel wall or the adventitia in previous studies.

Materials and Methods: DCE-MRI parameter agreement was analyzed in 110 symptomatic patients with $\geq 2 \mathrm{~mm}$ carotid plaque that underwent a 3 T carotid DCE-MRI examination. $K^{\text {trans }}$ was estimated in the entire vessel wall and adventitia. Twenty-three patients underwent carotid endarterectomy and were used for comparison with histological quantification of microvessel density of the plaque using CD31 immunohistochemistry. DCE-MRI parameters in the vessel wall regions were compared using Pearson's correlation coefficient, Bland-Altman analysis, and a two-sided paired samples t-test. Correlation of the DCE-MRI parameters with histology was studied using the Pearson's correlation coefficient.

Results: Median adventitial $K^{\text {trans }}$ was $5 \%$ higher $(P=0.003)$ than entire vessel wall $K^{\text {trans }}$, with no differences for other descriptive statistics. Vessel wall and adventitial $K^{\text {trans }}$ showed similar moderately strong correlations with plaque microvessel density on histology (Pearson's $\rho$ : 0.59-0.65 [P<0.003] and 0.52-0.64 [P<0.011], respectively).

Conclusion: The similar moderately strong correlations for vessel wall and adventitial $K^{\text {trans }}$ with microvessel density on histology suggested that both regions reflected plaque microvessel density. Care should to be taken when comparing absolute values between studies. Future studies incorporating thresholds for risk stratification need to agree upon standardization of DCE-MRI parameters.

Level of Evidence: 2

Technical Efficacy: Stage 2

J. MAGN. RESON. IMAGING 2017;46:1053-1059.

$\mathrm{R}_{\mathrm{n}}^{\mathrm{u}}$ upture of a vulnerable carotid atherosclerotic plaque may lead to an ischemic stroke, resulting in morbidity or even death of the patient. ${ }^{1}$ Several plaque features have been identified as important hallmarks of plaque vulnerability, including increased plaque microvasculature. ${ }^{2}$ These microvessels originate from the adventitia (the exterior part

View this article online at wileyonlinelibrary.com. DOI: 10.1002/jmri.25648

Received Oct 25, 2016, and in revised form Jan 11, 2017. Accepted for publication Jan 11, 2017

*Address reprint requests to: M.E.K., Department of Radiology and Nuclear Medicine, Maastricht University Medical Center, P.O. Box 5800, 6202 AZ Maastricht, The Netherlands. E-mail: eline.kooi@mumc.nl

From the ${ }^{1}$ Department of Radiology and Nuclear Medicine, Maastricht University Medical Center, Maastricht, The Netherlands; ${ }^{2}$ CARIM School for Cardiovascular Diseases, Maastricht University, Maastricht, The Netherlands; ${ }^{3}$ Department of Pathology, Maastricht University Medical Center, Maastricht, The Netherlands; ${ }^{4}$ Department of Neurology, Maastricht University Medical Center, Maastricht, The Netherlands; ${ }^{5}$ Department of Clinical Neurophysiology, Maastricht University Medical Center, Maastricht, The Netherlands; ${ }^{6}$ Department of Pathology, Academic Medical Center, Amsterdam, The Netherlands; and ${ }^{7}$ Department of General Surgery, Maastricht University Medical Center, Maastricht, The Netherlands 
of the vessel wall) and grow into the plaque tissue, ${ }^{3}$ supplying the plaque with nutrients and oxygen. The structural integrity of plaque microvasculature endothelium is impaired. ${ }^{4}$ Therefore, plaque microvessels may provide an entry point for inflammatory cells and erythrocytes and may cause destabilization of the plaque, ${ }^{5}$ leading to an increased risk of plaque rupture.

Dynamic contrast-enhanced magnetic resonance imaging (DCE-MRI) has emerged as a noninvasive technique to assess plaque microvasculature. With this technique, the microvasculature can be studied (semi-)quantitatively by studying the leakage of the contrast medium (CM) from the microvasculature into the plaque tissue. Previous research has been performed in specimens from patients undergoing a carotid endarterectomy (CEA). During CEA, the carotid plaque (ie, the intima) and (part of) the media is removed, leaving the remaining vessel wall including the adventitia in situ. These studies have already shown a correlation between the volume transfer coefficient, $K^{\text {trans }}$, a quantitative DCEMRI parameter reflecting microvessel flow, density, and permeability, and histological measurements of the plaque microvasculature as a reference. $^{6-9}$

A number of studies have investigated the relationship between plaque microvasculature and other features of plaque vulnerability, such as inflammation ${ }^{10-12}$ and the presence of intraplaque hemorrhage. ${ }^{13}$ The focus of these studies was either on the entire vessel wall ${ }^{6-8,10-12,14}$ or only on the outer layer of the vessel wall, the adventitia. ${ }^{9,13}$ Currently, no direct comparison between quantitative DCEMRI parameters from these two vascular regions has been performed. In addition, different descriptive statistics (eg, mean, median, or $75^{\text {th }}$ percentile) have been reported in these various studies. While mean and median values may be more suited to describe the overall state of the plaque microvasculature, the $75^{\text {th }}$ percentile may be more suited to reflect specific hotspots of increased plaque microvascularity.

The aim of the present study was to systematically investigate the agreement between quantitative DCE-MRI pharmacokinetic parameters derived from the entire vessel wall and the adventitial region in the same patient and correlate these parameters to the intraplaque microvessel endothelium density in histological specimens as a reference.

\section{Material and Methods}

\section{Study Population}

In this present prospective, cross-sectional study consecutive patients with an acute cerebrovascular event (stroke, transient ischemic attack [TIA], or amaurosis fugax) due to an ipsilateral carotid artery stenosis and a carotid plaque $\geq 2 \mathrm{~mm}$ on duplex ultrasonography were included.

Patients with a severe comorbidity (dementia, severe heart failure, ie, New York Heart Association class III-IV, severe pulmonary dysfunction dependent on oxygen supply, hemiparalysis, or complete aphasia) and standard contraindications for MRI, such as ferromagnetic/other electronic implants were excluded. Patients with severe renal disease (renal clearance $<30 \mathrm{ml} / \mathrm{min}$ ) were not eligible for contrast-enhanced MRI and were therefore excluded from the current analysis.

Medical history and medication use were ascertained at the time of subject enrolment. All study participants underwent carotid DCE-MRI of the symptomatic carotid plaque. Histological and MRI analysis was performed blinded to the other test results by randomization of the histological samples before analysis.

Approval of the local Institutional Ethical Review Board was obtained. Written informed consent was obtained from all patients before study inclusion.

\section{MRI}

MRI was performed with a 3T whole-body MRI system (Achieva, Philips Healthcare, Best, The Netherlands) using a dedicated 8channel carotid RF coil (Shanghai Chenguan Medical Technologies, Shanghai, China). Five MRI pulse sequences were used to facilitate delineation of plaque boundaries as described previously. ${ }^{15}$ For DCE-MRI, an end-diastolic ECG gated 3D $T_{1}$-TFE MRI pulse sequence was acquired centered at the position of the highest plaque burden with the following parameters: repetition/echo time 11.6/5.7 msec, flip angle $35^{\circ}$, field of view $130 \times 130 \mathrm{~mm}$, acquisition/reconstruction matrix $208 \times 206 / 512 \times 512$, five adjoining transversal slices, slice thickness $2 \mathrm{~mm} .{ }^{16}$ The temporal resolution was $\sim 20$ seconds per timeframe (dependent on heart rate). At the beginning of the third timeframe, a contrast medium (CM) $(0.1 \mathrm{mmol} / \mathrm{kg}$ gadobutrol [Gadovist, Bayer Healthcare, Berlin, Germany]) was injected with a power injector (Spectris Solaris, Medrad, Warrendale, PA) at $0.5 \mathrm{ml} / \mathrm{sec}$ followed by a $20-\mathrm{mL}$ saline chaser at the same rate. DCE-MR imaging was continued for 6 minutes after contrast injection.

\section{CEA and Histological Preparation}

Indication for CEA was based on the clinician's decision. Surgeons were instructed to remove the carotid plaque in one piece. Carotid endarterectomy specimens were collected after surgery and histological processing was performed as described previously. ${ }^{8}$ In short, after CEA the carotid plaques were immediately fixed in $10 \%$ buffered formalin, transversely cut in 3-mm slices, decalcified, embedded in paraffin, and cut in $4-\mu \mathrm{m}$ (transverse) slices. Colocalization of histopathological sections with DCE-MRI slices was performed using the longitudinal position relative to the carotid bifurcation and/or the narrowest carotid artery lumen as a reference. ${ }^{8}$ Plaque microvasculature was detected on coregistered slices with immunohistochemistry using primary antibodies against CD31 (clone JC70A, Dako North America, Carpinteria, CA), for identification of endothelial cells.

Plaque microvasculature was quantified on high spatial resolution digital images by using morphometric analysis software (QWin V3, Leica, Cambridge, UK). Plaque microvasculature was measured as the CD31-positive area surrounding a lumen. Relative density of microvessel endothelium was calculated by dividing the total CD31-positive area by the total plaque area. 

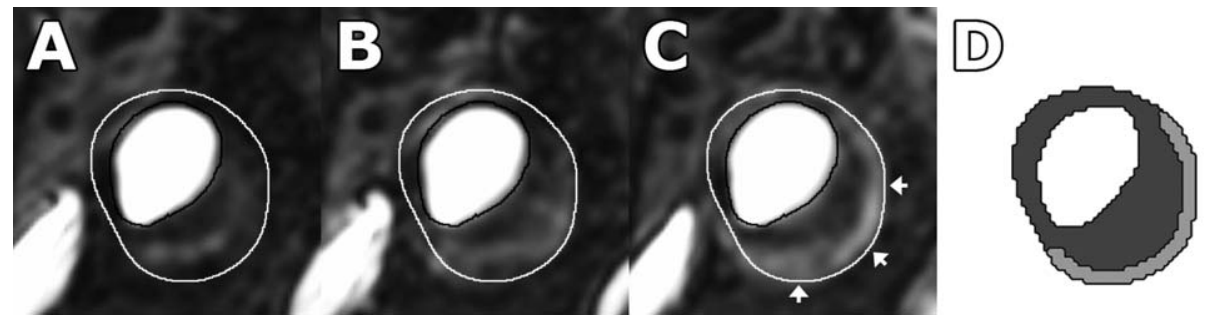

FIGURE 1: Signal enhancement of the carotid artery on DCE-MR images. DCE-MR images (A-C) from a patient with a severe stenosis of the internal carotid artery. The lumen boundary is shown in black, while the outer vessel wall is shown in white. Image A shows the carotid artery before contrast injection, while images B and C show the carotid artery 1 and 6 minutes after contrast injection, respectively. The adventitial region (all pixels within $0.625 \mathrm{~mm}$ of the outer wall contour in a region of the vessel wall with a wall thickness $>1.5 \mathrm{~mm}$ ) clearly shows stronger signal enhancement compared to the remaining vessel wall tissue. This ring of enhancement is attributed to the vasa vasorum, which origines from the adventitia. The result of the automatic vessel segmentation is shown in image $\mathbf{D}$. The adventitial region is depicted in light gray and the remaining vessel wall in dark gray.

\section{DCE-MRI Evaluation and Pharmacokinetic Modeling}

Both luminal and outer plaque contours were drawn as described previously. ${ }^{16}$ Luminal contours were drawn on the $3 \mathrm{D}$ time-offlight (TOF), precontrast $T_{1}$-weighted $\left(T_{1} \mathrm{w}\right)$ QIR TSE, postcontrast $T_{1} \mathrm{w}$ QIR TSE, or $T_{2} \mathrm{w}$ TSE MR images, in subsequent order. Outer vessel wall contours were drawn by using the precontrast $T_{1} \mathrm{w}$ QIR TSE, postcontrast $T_{1} \mathrm{w}$ QIR TSE, $T_{1} \mathrm{w}$ TFE or $T_{2} \mathrm{w}$ TSE MR images, in subsequent order. Contours from anatomic MRI acquisitions were transferred to the DCE-MR images. If necessary, contours were manually adjusted and individual timeframes shifted to correct for small patient displacements. Luminal contours were corrected to avoid partial volume effects, by keeping a sufficient distance from the vessel lumen. Outer plaque contours were corrected to include the adventitial vasa vasorum, which shows increased enhancement after contrast material administration. The entire vessel wall region was defined as the region between the luminal and outer wall contours. Adventitial region of the vessel wall was determined according to previously introduced criteria. ${ }^{13}$ According to these criteria, all pixels within $0.625 \mathrm{~mm}$ of the outer wall contour in a region of the vessel wall with plaque, which was defined as a wall thickness greater than $1.5 \mathrm{~mm}$. An example of the contours in an image is given in Fig. 1D.

Pharmacokinetic parameters were estimated using the Patlak model ${ }^{17}$ on a voxelwise basis as previously described ${ }^{8}$ with a phase-based population averaged vascular input function that was previously determined in the carotid artery. ${ }^{16}$ Shortly, CM concentrations in the plaque were determined from the signal intensity time course by using the Ernst equation and literature values for the longitudinal and transversal relaxation times of tissue ${ }^{18}$ and the $r_{1}$ and $r_{2}$ relaxation rates of the CM. ${ }^{19}$ Resulting $\mathrm{K}^{\text {trans }}$ distribution was analyzed by calculating the mean, median, and $75^{\text {th }}$ percentile. The median $95 \%$ confidence interval for $\mathrm{K}^{\text {trans }}$ was determined to estimate uncertainty in parameter estimation.

\section{Statistical Analysis}

Differences in clinical characteristics between CEA and non-CEA patients were investigated using a chi-square test (binary variables), independent samples $t$-test (continuous variables), or independent samples Kruskal-Wallis test (categorical variables), as appropriate. Mean, median, and $75^{\text {th }}$ percentile $K^{\text {trans }}$ values in two vessel wall regions (entire vessel wall versus adventitia) were compared using Pearson's correlation coefficient, a two-sided paired samples $t$-test, and Bland-Altman analysis. Mean, median, and $75^{\text {th }}$ percentile $K^{\text {trans }}$ from the entire vessel wall and adventitia were compared between CEA patients and non-CEA patients using an independent samples $t$-test. Association of mean, median, and $75^{\text {th }}$ percentile $\mathrm{K}^{\text {trans }}$ determined from the entire vessel wall and adventitial region with the relative microvessel density was assessed by calculation of Pearson's correlation coefficient. Correlation coefficients between 0.5 and 0.8 were considered moderately strong, while coefficients $>0.8$ were considered strong. All $P$-values below 0.05 were considered significant.

\section{Results}

\section{Patient Inclusion and Characteristics}

In total, 118 patients were included. Eight patients could not be analyzed due to artifacts and/or insufficient quality of the DCE-MR images. A total of 110 patients were used for analysis of DCE-MRI parameter agreement. Of these 110 patients, 23 patients underwent CEA and obtained specimens were used for histological validation of DCEMRI. Patient characteristics are displayed in Table 1. The mean time interval between the last symptoms and DCEMRI examination differed significantly between CEA and non-CEA patients $(20.9 \pm 5.2$ days vs. $41.6 \pm 2.1 ; P<$ 0.001 ). A significantly higher degree of stenosis on duplex ultrasonography, prevalence of hypertension, hypercholesterolemia, and statin use prior to the ischemic event was observed in CEA patients, while a significant higher age for patients not scheduled for CEA was observed. The interval between DCE-MRI and CEA was $<24$ hours.

\section{DCE-MRI}

Examples of DCE-MR images are given in Fig. 1. A moderately strong positive correlation (Table $2 ; n=110$ ) was found between $K^{\text {trans }}$ parameters from the entire vessel wall and adventitia for all descriptive statistics (Pearson's $\rho$ correlation coefficient range between 0.66 and $0.70, P<0.001$ ). Median adventitial $\mathrm{K}^{\text {trans }}$ was $5 \%$ larger than median vessel wall $\mathrm{K}^{\text {trans }}(P=0.003)$, while no significant differences were 


\section{TABLE 1. Baseline Characteristics of the Included Patients}

\begin{tabular}{|c|c|c|c|c|c|}
\hline & & $\begin{array}{l}\text { All } \\
\text { patients }\end{array}$ & $\begin{array}{l}\text { CEA } \\
\text { patients }\end{array}$ & $\begin{array}{l}\text { Non-CEA } \\
\text { patients }\end{array}$ & $P$-value \\
\hline Number of patients $[n]$ & & 110 & 23 & 87 & \\
\hline Age $[y]$ & & $69 \pm 8.4$ & $65 \pm 8.2$ & $70 \pm 8.4$ & $P=0.013$ \\
\hline Male sex $(\%)$ & & $75(68 \%)$ & $19(83 \%)$ & $56(64 \%)$ & $P=0.095$ \\
\hline Amaurosis fugax / TIA (\%) & & $68(62 \%)$ & $16(70 \%)$ & $52(60 \%)$ & $P=0.390$ \\
\hline Body mass index $\left[\mathrm{kg} / \mathrm{m}^{2}\right]$ & & $26.8 \pm 4.2$ & $26.9 \pm 3.4$ & $26.8 \pm 3.7$ & $P=0.942$ \\
\hline Current smoking status (\%) & & $22(20 \%)$ & $6(26 \%)$ & $16(18 \%)$ & $P=0.412$ \\
\hline Diabetes mellitus (\%) & & $19(17 \%)$ & $5(22 \%)$ & $14(16 \%)$ & $P=0.524$ \\
\hline Hypertension (\%) & & $70(64 \%)$ & $20(87 \%)$ & $50(58 \%)$ & $P=0.009$ \\
\hline Hypercholesterolemia (\%) & & $56(52 \%)$ & $18(82 \%)$ & $38(44 \%)$ & $P=0.002$ \\
\hline Prior statin use $(\%)^{\mathrm{a}}$ & & $62(56 \%)$ & $21(96 \%)$ & $41(48 \%)$ & $P<0.001$ \\
\hline Time between event and MRI [d] & & $37.3 \pm 22.0$ & $20.9 \pm 24.9$ & $41.6 \pm 19.6$ & $P<0.001$ \\
\hline \multirow[t]{3}{*}{ Carotid Stenosis (duplex ultrasonography $)^{\mathrm{a}}$} & $<50 \%$ & 53 & 0 & 53 & $P<0.001$ \\
\hline & $50-69 \%$ & 34 & 2 & 32 & \\
\hline & $70-99 \%$ & 21 & 21 & 0 & \\
\hline
\end{tabular}

Data are presented as mean \pm standard deviation or $n(\%)$.

${ }^{a}$ Data known for 108 out of 110 patients. Difference between CEA and non-CEA patients was investigated using a chi-square test, independent samples $t$-test, or independent samples Kruskal-Wallis test, as appropriate.

found for mean and $75^{\text {th }}$ percentile $\mathrm{K}^{\text {trans }}$ (Table 2; $n=110$ ). Bland-Altman plots showed no variation of agreement across the range of values between the two vascular regions (Fig. 2). No significant difference in uncertainty of parameter estimation for vessel wall $\mathrm{K}^{\text {trans }}$ and adventitial $\mathrm{K}^{\text {trans }}$ was found $(P=0.48)$.

No significant differences were found between CEA and non-CEA patients for mean, median, and $75^{\text {th }}$ percentile $\mathrm{K}^{\text {trans }}$ from the vessel wall and adventitia $(P \geq 0.09$, Table 3).

\section{Correlation With Histology}

An example of a histological image of the microvasculature is shown in Fig. 3. The blood perfusion-vessel permeability product $\mathrm{K}^{\text {trans }}$ determined from both the entire vessel wall (Pearson's $\rho$ between 0.59 and $0.65, P<0.003$ ) and the adventitial (Pearson's $\rho 0.52$ to $0.64, P<0.011$ ) region showed similar moderately strong positive correlation coefficients with the plaque microvasculature in the histological specimens (Table $4 ; n=23$ ).

\section{Discussion}

The present study showed that $\mathrm{K}^{\text {trans }}$ determined from two regions of the vascular wall (ie, the entire vessel wall and the adventitia only) have similar moderately strong correlations with histological microvessel density in the plaque as a reference. A moderately strong positive correlation between vessel wall and adventitial $\mathrm{K}^{\text {trans }}$ was found with a significantly higher median adventitial $\mathrm{K}^{\text {trans }}$ compared to median vessel wall $\mathrm{K}^{\text {trans }}$. Bland-Altman plots did not show variation of agreement across the range of values. Therefore, we showed that DCE-MRI parameters of both the entire vessel

TABLE 2. Pharmacokinetic DCE-MRI Parameters' Agreement

\begin{tabular}{|c|c|c|c|c|}
\hline Parameter & Vessel wall & Adventitia & Pearson's $\rho$ & $P$-value ${ }^{\text {a }}$ \\
\hline Mean $\mathrm{K}^{\mathrm{trans}}\left[\mathrm{min}^{-1}\right]$ & $0.055 \pm 0.001$ & $0.057 \pm 0.002$ & $0.70(P<0.001)$ & 0.17 \\
\hline Median $\mathrm{K}^{\text {trans }}\left[\mathrm{min}^{-1}\right]$ & $0.037 \pm 0.001$ & $0.039 \pm 0.001$ & $0.66(P<0.001)$ & $<0.01$ \\
\hline $75^{\text {th }}$ Percentile $K^{\text {trans }}\left[\min ^{-1}\right]$ & $0.066 \pm 0.002$ & $0.068 \pm 0.002$ & $0.68(P<0.001)$ & 0.20 \\
\hline \multicolumn{5}{|c|}{$\begin{array}{l}\text { Parameter agreement of } \mathrm{K}^{\text {trans }} \text { (mean } \pm \text { standard error) was investigated using Pearson's rank correlation coefficient and two-sided } \\
\text { paired samples } t \text {-test in } 110 \text { patients. } \\
\text { a } P \text {-value of two-sided paired samples } t \text {-test. }\end{array}$} \\
\hline
\end{tabular}


van Hoof et al.: Correlation Between DCE-MRI \& Histology
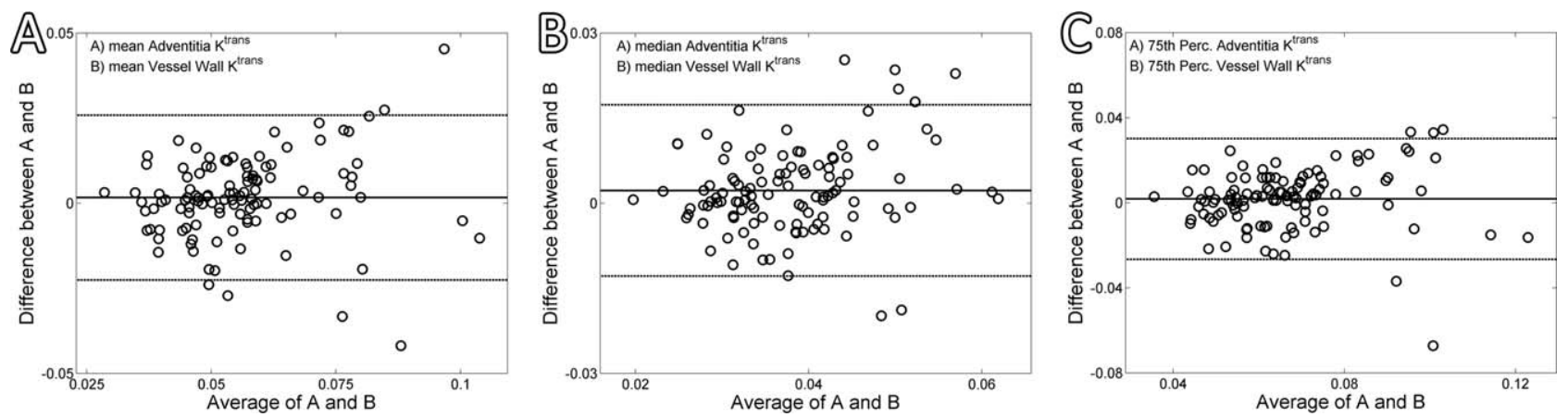

FIGURE 2: Bland-Altman plots of different vascular regions. Bland-Altman plots of mean (A), median (B), and $75^{\text {th }}$ percentile (C) $\mathrm{K}^{\text {trans }}$ values determined from the adventitia and entire vessel wall for patients with $\geq \mathbf{2} \mathbf{m m}$ carotid plaque. The mean difference is indicated by the black solid line and the $95 \%$ confidence interval of the mean difference by the dashed lines. Plots showed no variation of agreement across the range of values.

wall, as well as the adventitial region, can be representative for the microvessel density of the symptomatic atherosclerotic plaque.

We observed a slightly higher value of median $K^{\text {trans }}$ in the adventitial region compared to the entire vessel wall. A higher median value in the adventitial region is in line with the concept that plaque microvessels originate from this region and expand with disease progression. ${ }^{5,20}$ In contrast, no significant differences between these two regions were found for mean and $75^{\text {th }}$ percentile $K^{\text {trans }}$. The $75^{\text {th }}$ percentile $\mathrm{K}^{\text {trans }}$ may be more representative for microvascular hotspots, which will most likely be predominantly present in the adventitial part of the entire vessel wall. The mean $K^{\text {trans }}$ was closer to the $75^{\text {th }}$ percentile value than the median value, and may thus also have been significantly influenced by hotspots. Therefore, the mean and $75^{\text {th }}$ percentile $\mathrm{K}^{\text {trans }}$ from the entire vessel wall might be more representative for the adventitial part of the entire vessel wall.

Based on the moderately strong positive correlations between different $\mathrm{K}^{\text {trans }}$ parameters, we can conclude that similar results regarding the association of DCE-MRI with either histology, other imaging modalities, or clinical parameters can be expected, regardless of the $\mathrm{K}^{\text {trans }}$ descriptive that is being reported. However, care should be taken when directly comparing absolute $\mathrm{K}^{\text {trans }}$ values between different studies, since the median adventitial $\mathrm{K}^{\text {trans }}$ is significantly higher than that of the vessel wall. For the determination of appropriate thresholds that can be used in clinical studies, investigators need to agree upon standardization of parameters.

Previously, it was demonstrated that symptomatic patients with a higher degree of carotid stenosis have a more vulnerable plaque phenotype (ie, higher prevalence of intraplaque hemorrhage and a thin and/or ruptured fibrous cap and a larger lipid-rich necrotic core percentage and smaller fibrous tissue percentage) ${ }^{21}$ In contrast, in the present study we did not find significant differences in $K^{\text {trans }}$ values between patients who were scheduled for CEA (ie, with a significantly higher degree of carotid stenosis) and patients only receiving best medical treatment. Therefore, plaque microvasculature may already be increased in an earlier stage of the disease, which is in line with previous results from atherosclerotic plaques of the coronary arteries. ${ }^{22}$

The correlation between histological measurements of plaque microvasculature and DCE-MRI of carotid atherosclerosis of various regions of the vascular wall has been

TABLE 3. Comparison of DCE-MRI Parameters Between CEA and Non-CEA Patients

\begin{tabular}{|c|c|c|c|c|}
\hline & & $\begin{array}{l}\text { CEA patients } \\
{[n=23]}\end{array}$ & $\begin{array}{l}\text { Non-CEA patients } \\
{[n=87]}\end{array}$ & $P$-value \\
\hline \multirow[t]{3}{*}{ Vessel wall $\mathrm{K}^{\text {trans }}$} & Mean $\left[\min ^{-1}\right]$ & $0.051 \pm 0.002$ & $0.057 \pm 0.002$ & 0.09 \\
\hline & Median $\left[\min ^{-1}\right]$ & $0.035 \pm 0.002$ & $0.037 \pm 0.001$ & 0.21 \\
\hline & $75^{\text {th }}$ Percentile $\left[\min ^{-1}\right]$ & $0.061 \pm 0.002$ & $0.067 \pm 0.002$ & 0.17 \\
\hline \multirow[t]{3}{*}{ Adventitial wall $\mathrm{K}^{\text {trans }}$} & Mean $\left[\min ^{-1}\right]$ & $0.057 \pm 0.002$ & $0.057 \pm 0.002$ & 0.95 \\
\hline & Median $\left[\min ^{-1}\right]$ & $0.040 \pm 0.002$ & $0.039 \pm 0.001$ & 0.52 \\
\hline & $75^{\text {th }}$ Percentile $\left[\mathrm{min}^{-1}\right]$ & $0.069 \pm 0.003$ & $0.067 \pm 0.002$ & 0.68 \\
\hline
\end{tabular}




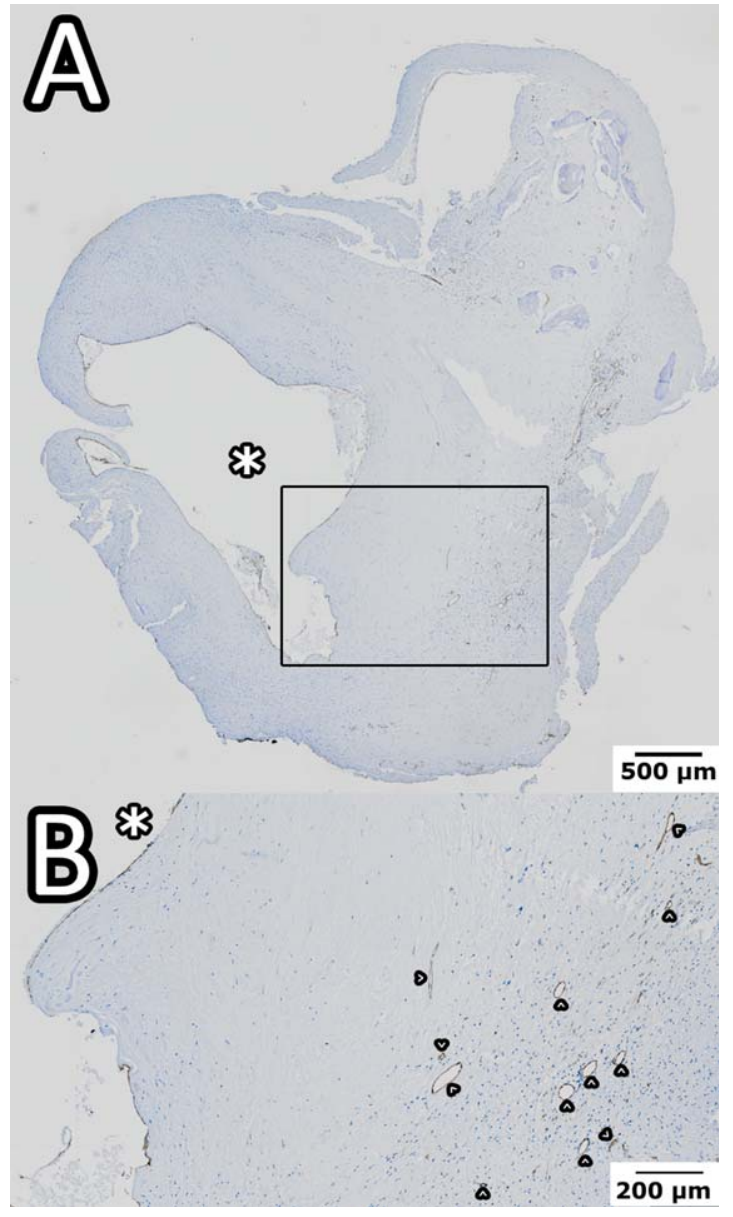

FIGURE 3: CD31 immunohistochemistry of the atherosclerotic plaque microvasculature. The microvessels can be observed in the CD31 immunohistochemistry slice. An overview of the entire slice is given in A. The vessel lumen is indicated by the white asterisk. Close-up of microvessels of the region indicated by the box is given in B and shows CD31-positive microvessels in brown that are indicated by arrowheads.

investigated in other studies. Kerwin et al showed a strong positive correlation between vessel wall $\mathrm{K}^{\text {trans }}$ with the microvessel endothelium density on histology. ${ }^{6,7}$ In addition, Gaens et al showed a strong positive correlation between mean vessel wall $\mathrm{K}^{\text {trans }}$ and the mean endothelial microvessel density on histology in 13 patients. ${ }^{8}$ A moderate correlation with relative microvessel cross-sectional area between plaque microvasculature and adventitial $\mathrm{K}^{\text {trans }}$ was reported in a study of 25 patients. ${ }^{9}$ Correlation coefficients with histology of all descriptive statistics in the present study were thus comparable and within the range of previously reported studies. ${ }^{6-9}$

A limitation of our study is the absence of the adventitia in the carotid plaque specimens obtained during CEA. Since only the intimal region containing the plaque and part of the media are surgically removed during CEA, the correlation of the microvessel density of the adventitia with $\mathrm{K}^{\text {trans }}$ cannot be investigated. The similar correlations of entire vessel wall and adventitial $\mathrm{K}^{\text {trans }}$ with measurements of the plaque microvasculature on histology, and the moderately strong correlation between $\mathrm{K}^{\text {trans }}$ parameters, suggest that the microvasculature in the plaque is closely related to that in the surrounding adventitia, in line with previous results from autopsy studies of coronary plaques. ${ }^{22} \mathrm{~A}$ true validation of adventitial $\mathrm{K}^{\text {trans }}$ can only be performed in autopsy studies.

Another limitation of our study is that only patients with a recent ischemic cerebrovascular event were included. Therefore, in our study we were unable to relate DCE-MRI findings to clinical symptoms. Last, because of the crosssectional study design, we could not investigate the value of DCE-MRI to predict stroke. To investigate the value of DCE-MRI for risk stratification of patients, a longitudinal study is warranted.

In conclusion, our current study showed a moderately strong positive correlation for mean, median, and $75^{\text {th }}$ percentile $\mathrm{K}^{\text {trans }}$ determined from the entire vessel wall and adventitial region with the relative microvessel density in histological specimens as a reference standard. This showed that both vascular regions can be representative for plaque microvessel density in symptomatic patients with severe carotid stenosis. Moderately strong correlation coefficients of DCE-MRI parameters from the vessel wall and adventitia were observed, with larger median $\mathrm{K}^{\text {trans }}$ values for the adventitial region. Future studies incorporating thresholds for risk stratification using DCE-MRI need to agree upon standardization of parameters used for analysis of DCEMRI data.

\section{TABLE 4. Correlation of DCE-MRI Parameters With Histology in 23 Patients Who Underwent Carotid Endarterectomy}

\begin{tabular}{lll} 
& $\begin{array}{l}\text { Pearson's rank correlation } \\
\text { coefficient } \boldsymbol{\rho} \text { for vessel wall } \mathbf{K}^{\text {trans }}\end{array}$ & $\begin{array}{l}\text { Pearson's rank correlation } \\
\text { coefficient } \boldsymbol{\rho} \text { for adventitial } \mathbf{K}^{\text {trans }}\end{array}$ \\
\hline Mean & $0.62(P<0.01)$ & $0.62(P<0.01)$ \\
\hline Median & $0.59(P=0.01)$ & $0.52(P=0.01)$ \\
$75^{\text {th }}$ Percentile & $0.65(P=0.01)$ & $0.64(P<0.01)$
\end{tabular}

Pearson's rank correlation coefficient (and corresponding $P$-values) of pharmacokinetic DCE-MRI parameters with the relative microvessel density (total CD31-positive area divided by the total plaque area) as determined from carotid endarterectomy specimens. 


\section{Acknowledgments}

This research was performed within the framework of CTMM, the Center for Translational Molecular Medicine (www.ctmm.nl), project PARISk (grant 01C-202), and supported by the Dutch Heart Foundation.

The authors thank R.J. van der Geest (Department of Radiology, Leiden University Medical Center, Leiden, The Netherlands) for providing the VesselMASS analysis software package. M.E. Kooi and J.E. Wildberger are supported by Stichting De Weijerhorst. M.E. Kooi is supported by an Aspasia Grant 015.008.047 from the Netherlands Organization for Scientific Research.

\section{References}

1. Mozaffarian D, Benjamin EJ, Go AS, et al. Heart disease and stroke statistics-2015 update: a report from the American Heart Association. Circulation 2015;131:e29-e322.

2. Moreno PR, Purushothaman K-R, Sirol M, et al. Neovascularization in human atherosclerosis. Circulation 2006;113:2245-2252.

3. Kumamoto $M$, Nakashima $Y$, Sueishi K. Intimal neovascularization in human coronary atherosclerosis: its origin and pathophysiological significance. Hum Pathol 1995;26:450-456.

4. Virmani R, Kolodgie FD, Burke AP, et al. Atherosclerotic plaque progression and vulnerability to rupture: angiogenesis as a source of intraplaque hemorrhage. Arterioscler Thromb Vasc Biol 2005;25: 2054-2061.

5. Sluimer JC, Daemen MJ. Novel concepts in atherogenesis: angiogenesis and hypoxia in atherosclerosis. J Pathol 2009;218:7-29.

6. Kerwin W. Quantitative magnetic resonance imaging analysis of neovasculature volume in carotid atherosclerotic plaque. Circulation 2003; 107:851-856.

7. Kerwin WS, O'Brien KD, Ferguson MS, et al. Inflammation in carotid atherosclerotic plaque: a dynamic contrast-enhanced MR imaging study. Radiology 2006;241:459-468.

8. Gaens ME, Backes WH, Rozel S, et al. Dynamic contrast-enhanced mr imaging of carotid atherosclerotic plaque: model selection, reproducibility, and validation. Radiology 2013;266:271-279.

9. Kerwin WS, Oikawa M, Yuan C, et al. MR imaging of adventitial vasa vasorum in carotid atherosclerosis. Magn Reson Med 2008;59:507-514.
10. Truijman MT, Kwee RM, van Hoof RH, et al. Combined 18F-FDG PETCT and DCE-MRI to assess inflammation and microvascularization in atherosclerotic plaques. Stroke 2013;44:3568-3570.

11. Calcagno C, Ramachandran S, Izquierdo-Garcia D, et al. The complementary roles of dynamic contrast-enhanced $\mathrm{MRI}$ and $18 \mathrm{~F}$ fluorodeoxyglucose PET/CT for imaging of carotid atherosclerosis. Eur J Nucl Med Mol Imaging 2013;40:1884-1893.

12. Wang J, Liu $H$, Sun J, et al. Varying correlation between 18Ffluorodeoxyglucose positron emission tomography and dynamic contrast-enhanced MRI in carotid atherosclerosis: implications for plaque inflammation. Stroke 2014;45:1842-1845.

13. Sun J, Song $Y$, Chen $H$, et al. Adventitial perfusion and intraplaque hemorrhage: a dynamic contrast-enhanced MRI study in the carotid artery. Stroke 2013;44:1031-1036.

14. O'Brien KD, Hippe DS, Chen $\mathrm{H}$, et al. Longer duration of statin therapy is associated with decreased carotid plaque vascularity by magnetic resonance imaging. Atherosclerosis 2015;245:74-81.

15. Truijman MT, Kooi ME, van Dijk AC, et al. Plaque At RISK (PARISK): prospective multicenter study to improve diagnosis of high-risk carotid plaques. Int J Stroke 2014;9:747-754.

16. van Hoof RH, Hermeling E, Truijman MT, et al. Phase-based vascular input function: Improved quantitative DCE-MRI of atherosclerotic plaques. Med Phys 2015;42:4619.

17. Patlak CS, Blasberg RG, Fenstermacher JD. Graphical evaluation of blood-to-brain transfer constants from multiple-time uptake data. J Cereb Blood Flow Metab 1983;3:1-7.

18. Stanisz GJ, Odrobina EE, Pun J, et al. T1, T2 relaxation and magnetization transfer in tissue at 3T. Magn Reson Med 2005;54:507-512.

19. Pintaske J, Martirosian P, Graf H, et al. Relaxivity of gadopentetate dimeglumine (Magnevist), gadobutrol (Gadovist), and gadobenate dimeglumine (MultiHance) in human blood plasma at 0.2, 1.5, and 3 Tesla. Invest Radiol 2006;41:213-221.

20. Sluimer JC, Gasc JM, van Wanroij JL, et al. Hypoxia, hypoxiainducible transcription factor, and macrophages in human atherosclerotic plaques are correlated with intraplaque angiogenesis. J Am Coll Cardiol 2008;51:1258-1265.

21. Kwee RM, van Oostenbrugge RJ, Prins $M H$, et al. Symptomatic patients with mild and moderate carotid stenosis: plaque features at $\mathrm{MRI}$ and association with cardiovascular risk factors and statin use. Stroke 2010;41:1389-1393.

22. Sluimer JC, Kolodgie FD, Bijnens AP, et al. Thin-walled microvessels in human coronary atherosclerotic plaques show incomplete endothelial junctions relevance of compromised structural integrity for intraplaque microvascular leakage. J Am Coll Cardiol 2009;53:1517-1527. 